\title{
MODULAÇÃO DA MARCHA AQUÁTICA PELA RESISTÊNCIA E SEUS EFEITOS SOBRE O COMPORTAMENTO MOTOR
}

\section{AQUATIC GAIT MODULATION BY RESISTANCE AND ITS EFFECTS ON MOTOR BEHAVIOR}

\author{
Vanessa Z. Rebutini ${ }^{1}$, Elisângela V. Rodrigues², Leonardo Maiola ${ }^{3}$, Vera L. Israel ${ }^{4}$
}

\begin{abstract}
RESUMO:
O meio aquático determina diversas modificações nos gestos motores, estas mudanças estão diretamente ligadas às características e princípios físicos que regem este meio. A marcha é um ato motor funcional adquirido na infância, repetido e automatizado. O objetivo é identificar como a resistência da água interfere no comportamento motor na marcha aquática. Método: realizou-se uma revisão bibliográfica na base de dados da Bireme (LILACS, IBECS, MEDLINE, Biblioteca Cochrane, SciELO). Os artigos estudados apresentam que a marcha pode ser definida e influenciada pelo seu histórico evolutivo, pelas variáveis do ambiente aquático (profundidade, densidade, fluxo), pelas caracteríticas do corpo em deslocamento (forma, composição, peso, etc). Os achados apontam para uma resposta somatosensorial, que se efetiva pela ação em função da composição, da forma, do peso, etc.
\end{abstract}

Palavras-chave: água; marcha; cinemática; atividade motor.

\section{ABSTRACT:}

The aquatic environment causes many modifications in motor gestures, changes directly linked to the characteristics and physical principles that govern this medium. Gait is a functional motor act acquired in childhood, repeated and automated. The objective of this study was to identify how the resistance of the water interferes with the motor behavior in aquatic gait. Methods: a review was carried out using the Bireme database (LILACS, IBECS, MEDLINE, Cochrane Library, SciELO). The articles studied showed that gait could be defined and influenced by its historical evolution, the variables of the water environment (depth, density, flow) and the characteristics of the body being displaced (shape, composition, weight, etc). The findings point to a somatosensory response that is enabled by the action as a function of the composition, shape, weight, etc.

Key words: water; gait; kinematics; motor activity.

\section{INTRODUÇÃO}

Os estudos envolvendo movimento humano no ambiente aquático têm grande relevância nas pesquisas de treinamento e reabilitação devido às diferentes propriedades físicas e mecânicas que este meio impõe ${ }^{1}$. Dentre essas propriedades, aqui destaca-se a resistência aquática: característica determinante quando consideramos os diversos deslocamentos possíveis neste meio.
O desempenho do deslocamento no meio aquático pode ser descrito pela interação que o corpo tem com a água, visando vencer as resistências que a água lhe oferece. Um dos efeitos resistivos negativos mais influentes é o arrasto hidrodinâmico, definido pela ação opositiva da água ao deslocamento do corpo imerso ${ }^{2}$. Esse arrasto se efetiva pela relação entre a forma ou área de contato frontal do corpo imerso e pela velocidade em que esse corpo se desloca ${ }^{3}, 4$, relação que se dá em

1 Mestre pelo Programa de Pós-Graduação em Educação Física, Universidade Federal do Paraná (UFPR), Curitiba, PR - Brasil.

2 Mestre pelo Programa de Pós-Graduação em Educação Física, Universidade Federal do Paraná (UFPR); Docente no Instituto Federal do Paraná, Curitiba, PR.

3 Aluno do Programa de Pós-Graduação em Educação Física, Universidade Federal do Paraná (UFPR), Curitiba, PR - Brasil.

4 Doutora, Centro de Estudos do Movimento e Postura Humana (CEMPH), Universidade Federal do Paraná - Litoral (UFPR-Litoral), Matinhos, PR - Brasil.

Correspondência para: vanerebutini@hotmail.com

Suggested citation: Rebutini VZ, et al. Aquatic gait modulation by resistance and its effects on motor behavior. J. Hum. Growth Dev. 2012; 22(3): 378-387

Manuscript submitted Nov 05 2011, accepted for publication Aug 022012. 
proporções quadradas, ou seja, a resistência aumenta exponencialmente segundo o incremento na velocidade ${ }^{5}$.

Outro efeito a ser considerado é o da viscosidade, que resulta da interação e agrupamento das moléculas segundo sua agitação térmica ${ }^{2}$, que depende da temperatura da água, tornando-se um fator facilitador ou dificultador do deslocamento neste meio ${ }^{6}$. Além dos citados, o fluxo turbulento, caracterizado pelo movimento desordenado da água, também atua como um elemento resistivo ao deslocamento neste ambiente; entretanto, sua ação irá favorecê-lo quando a direção do fluxo for igual a do movimento e o dificultará quando estiver contrário ao movimento ${ }^{7}$.

A ação da resistência do meio aquático propicia também o denominado arrasto ativo - movimento de propulsão criado pelo próprio corpo em deslocamento através dos movimentos dos membros. Tal movimento de propulsão pode ser explicado pelas seguintes teorias: a primeira baseia-se na terceira lei de Newton (ação e reação) e estabelece a propulsão dos corpos pela reação da água ao movimento (ao empurrar a água para trás, esta exerce uma força de igual magnitude para impulsionar os corpos à frente); a segunda teoria baseia-se no princípio de Bernoulli, a qual define a existência de uma força de sustentação criada pela diferença de pressão entre os lados opostos das mãos, quando movimentadas "varrendo" a água: maior pressão na palma e menor no dorso da mão (a diferença de pressão produz uma força de sustentação perpendicular à direção do fluxo de água que passa pelas mãos e o corpo é impulsionado à frente), sujeita à influência do ângulo de ação das mãos no movimento, sendo este principal ou auxiliar ${ }^{3}$.

Uma das formas de deslocamento possível no ambiente aquático, que estará sob a ação das propriedades descritas, é a marcha: habilidade motora fundamental e gesto motor habitual automatizado, composta por movimentos integrados do corpo e definida pelos sucessivos desequilíbrios do corpo que determinam o avanço à frente ${ }^{8}$. No ser humano normal, o padrão de marcha é adquirido e desenvolvido na infância, de modo que o sistema sensório motor torna-se muito adaptado e gera automaticamente um conjunto repetitivo de comandos de controle motor sobre os segmentos, para permitir que a pessoa caminhe sem esforço consciente ${ }^{1}$.

Mesmo sendo um ato complexo e automatizado da vida diária, a marcha pode sofrer interferência e modificações nos padrões de movimento segundo os tipos de superfície e ambiente em que é realizada ${ }^{9}$. Para o estudo da marcha, utilizam-se parâmetros sob a ótica da biomecânica (variáveis cinemáticas lineares e angulares/articulares: velocidade, deslocamento, aceleração, etc), do comportamento motor (orientação ou controle postural, manipulação e locomoção - padrões de movimento, nível de habilidade, etc) e pela interação de ambos.
O deslocamento angular, por exemplo, descreve as amplitudes dos movimentos articulares durante a marcha. As variáveis cinéticas incluem a força de reação ao solo, momentos de força, potência e trabalho das articulações durante o movimento ${ }^{10}$. As modificações cinemáticas, dinâmicas ou neuromusculares é que determinam a interferência do meio no qual o movimento acontece ${ }^{10}$, permitindo conclusões e propostas para o mecanismo desta influência.

No ambiente aquático, assim como no terrestre, a marcha é executada com o indivíduo na vertical, com variações de direção e sentido². Devido às propriedades físicas da água descritas acima, o comportamento das variáveis da marcha em água diferencia-se das do solo e entre as diferentes profundidades ${ }^{11}$, determinando ajustes que variam de acordo com as características do indivíduo e com a idade ${ }^{12}$. A marcha pode ser facilitada se a temperatura da água estiver elevada e, portanto, sua viscosidade diminuída; o arrasto ativo, por sua vez, pode determinar uma maior eficiência da marcha de acordo com a aplicação do membro propulsor - nesse caso, utiliza-se o auxílio dos braços. Assim, seja facilitando ou oferecendo resistência à execução dos movimentos, o meio aquático demanda que ocorram ajustes em relação ao comportamento motor terrestre do indivíduo como a maior ativação dos eretores da espinha e do reto femoral ${ }^{13}$.

Os ajustes, observáveis e definidos pelos meios aquático e terrestre, podem ser avaliados pela ótica da biomecânica e do comportamento motor. Há uma ênfase quanto aos estudos sob a perspectiva biomecânica, mas ao considerar a ótica do comportamento motor, existem poucos estudos que tentam argumentar a respeito, especificamente no meio aquático.

Assim, o objetivo é verificar como a resistência aquática promove adequações do comportamento motor na marcha aquática.

\section{MÉTODO}

Trata-se de pesquisa em base de dados, realizada no período de setembro de 2010 a novembro de 2011 na base de dados da Bireme (que englobam as seguintes bases de dados LILACS, IBECS, MEDLINE, Biblioteca Cochrane, SciELO) ), com o objetivo de encontrar estudos relacionados à marcha no ambiente aquático e terrestre. Inicialmente foram escolhidas as palavras-chave encontradas no sistema DeCS: flow mechanics, gait, biomechanics, motor behavior e physical aquatic, combinadas em grupos de três palavras para a pesquisa. Esta escolha resultou em 68 artigos: 35 destes foram excluídos e os 33 restantes não abrangiam os estudos sobre marcha no ambiente aquático - motivo para abandono desta pesquisa.

Novas buscas foram realizadas com as palavras-chave water, walking and kinematics, dispos- 
tas em busca única. Foram inicialmente identificadas 36 publicações potencialmente elegíveis nesta revisão. Os critérios de inclusão foram: disponibilidade de acesso livre online ou pelo portal da Capes, pesquisas realizadas em seres humanos, trabalhos publicados nos últimos 10 anos, estudos publicados em português e/ou inglês e estudos realizados no meio aquático e terrestre.

Em seguida excluíram-se artigos que, pela leitura dos títulos e resumos, atenderam aos critérios de exclusão: estudos realizados há mais de dez anos (8 artigos), realizados com animais (9 artigos), estudos com populações com comorbidades do Sistema Nervoso Central e/ou sistema músculo-esquelético ( 3 artigos).

Os 16 artigos restantes foram divididos aleatória e equitativamente entre os autores, agrupados por objetivo de pesquisa e descritos por ordem cronológica.

\section{RESULTADOS}

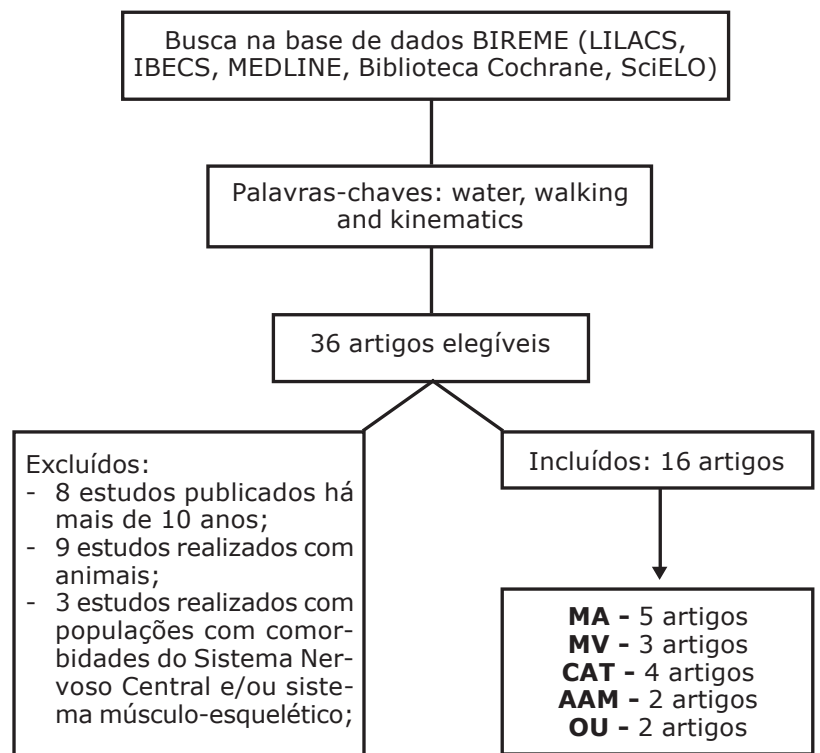

Figura 1 - Fluxograma do Estudo. MA - marcha aquática, atividade muscular e cinemática. MV - marcha em terrenos variados e diferenças biomecânicas. CAT comparação marcha aquática e terrestre. AAM - análise antropológica da marcha humana. OU - outros.

Os estudos encontrados foram agrupados segundo seus objetivos de pesquisa, além da sequência cronológica: MA - marcha aquática, atividade muscular e cinemática (5 artigos); MV - marcha em terrenos variados e diferenças biomecânicas ( 3 artigos); CAT - comparação marcha aquática e terrestre (4 artigos); AAM - análise antropológica da marcha humana (2 artigos); OU - outros (2 artigos).

Os artigos do grupo MA apresentaram que há um aumento na ativação muscular no ambiente aquático segundo: a carga e a velocidade do movimento ${ }^{5}$ a velocidade do fluxo da água e a estabilidade $^{1}$; o deslocamento e postura ${ }^{13}$; o posicionamento de membros superiores, influência de peso, nível de imersão, área do corpo e velocidade ${ }^{11}$.
Sobre as variações de terreno e diferenças biomecânicas (MV), os artigos demonstraram que as interferências, que alteram parâmetros dos movimentos, podem ser: pela inclinação e modificação da composição da superfície de tráfego²; pela adição de dupla tarefa, cognitivas e/ou motoras concomitantes, com ou sem ajuste por feedback ${ }^{3}$. No entanto, também foram encontrados resultados que demonstram que há similaridade de comportamento de fatores cinemáticos entre uma superfície irregular e a plana ${ }^{4}$.

Quando comparados os dois tipos de meio em que a marcha pode ser realizada, aquático e terrestre (CAT), os artigos apresentaram a variação dos momentos articulares segundo a diferença de carga corporal, influenciada pelos meios ${ }^{6}$; a redução dos valores de força verticais ${ }^{6}$ e do impacto na água ${ }^{5}$; o aumento dos momentos articulares e das ativações musculares em função do aumento da velocidade de deslocamento na água ${ }^{6}$; a redução na amplitude articular do movimento no ambiente aquático ${ }^{19,18}$ ou a manutenção desta7; a diferença da ação articular de tornozelo na marcha aquática - apoio plano ${ }^{18}$ e aumento de flexão plantar nas demais fases ${ }^{19}$; a variação, entre os meios, da característica de velocidade de execução ${ }^{18} ; 0$ aumento na ativação muscular para mover o corpo à frente, na água, contra a resistência ${ }^{6}$.

Por fim, os artigos que estabelecem uma análise antropológica da marcha humana (AAM) defendem que a bipedalidade tem origem em termos de melhorias da locomoção: a redução do custo no andar em quatro apoios, para que grandes distâncias fossem cobertas em velocidade e com baixo desgaste ${ }^{8}$; na troca da locomoção bípede, porém com joelhos e tornozelos flexionados (dispendioso na marcha terrestre, mas facilitador no ambiente aquático), pela ereta? .

Figura 2: estudos encontrados, organizados por ano, tipo e base de dados

\begin{tabular}{|c|c|c|c|}
\hline Estudo & Ano & $\begin{array}{l}\text { Tipo de } \\
\text { estudo }\end{array}$ & $\begin{array}{l}\text { Base de dados } \\
\text { encontrada }\end{array}$ \\
\hline $\begin{array}{c}\text { Miyoshi et al. } \\
\text { MA }\end{array}$ & 2006 & experimental & MEDLINE \\
\hline $\begin{array}{l}\text { Roesler et al. } \\
\text { MA }\end{array}$ & 2006 & experimental & MEDLINE \\
\hline $\begin{array}{l}\text { Chevutschi et al. } \\
\text { MA }\end{array}$ & 2007 & experimental & MEDLINE \\
\hline $\begin{array}{l}\text { Masumoto; Mercer } \\
\text { MA }\end{array}$ & 2008 & revisão & MEDLINE \\
\hline $\begin{array}{l}\text { Kotani et al. } \\
\text { MA }\end{array}$ & 2009 & experimental & MEDLINE \\
\hline $\begin{array}{l}\text { Cham; Redfern } \\
\text { MV }\end{array}$ & 2002 & experimental & MEDLINE \\
\hline $\begin{array}{l}\text { Wade; Redfern } \\
\text { MV }\end{array}$ & 2007 & experimental & MEDLINE \\
\hline $\begin{array}{l}\text { Verhoeff et al. } \\
\text { MV }\end{array}$ & 2009 & experimental & MEDLINE \\
\hline $\begin{array}{l}\text { Miyoshi et al.; } \\
\text { CAT }\end{array}$ & 2009 & experimental & MEDLINE \\
\hline $\begin{array}{l}\text { Miyoshi et al. } \\
\text { CAT }\end{array}$ & 2005 & experimental & MEDLINE \\
\hline $\begin{array}{l}\text { Barela et al. } \\
\text { CAT }\end{array}$ & 2006 & experimental & MEDLINE \\
\hline $\begin{array}{l}\text { Barela; Duarte } \\
\text { CAT }\end{array}$ & 2008 & experimental & MEDLINE \\
\hline $\begin{array}{l}\text { Preuschoft } \\
\text { AAM }\end{array}$ & 2004 & revisão & MEDLINE \\
\hline $\begin{array}{l}\text { Kuliukas et al. } \\
\text { AAM }\end{array}$ & 2009 & experimental & MEDLINE \\
\hline $\begin{array}{l}\text { House et al. } \\
\text { Ou }\end{array}$ & 2004 & experimental & MEDLINE \\
\hline $\begin{array}{l}\text { Prendergast; Lee } \\
\text { OU }\end{array}$ & 2006 & revisão & MEDLINE \\
\hline
\end{tabular}


Figura 3: descrição de objetivos, métodos e desfecho para artigos MA - marcha aquática, atividade muscular e cinemática

\begin{tabular}{|c|c|c|c|c|}
\hline Estudo & Ano & Objetivo & Método & Desfecho \\
\hline $\begin{array}{c}\text { Miyoshi et al. } \\
\text { MA }\end{array}$ & 2006 & $\begin{array}{l}\text { Investigar as ativações } \\
\text { relacionados aos músculos } \\
\text { sinergéticos da planti-flexão do } \\
\text { tornozelo, enquanto os sujeitos } \\
\text { andavam na água. }\end{array}$ & $\begin{array}{l}10 \text { voluntários saudáveis; } \\
\text { caminhada na agua com } 3 \\
\text { diferentes cargas e } 4 \\
\text { diferentes velocidades; } \\
\text { nível da água na axila. } \\
\text { EMG dos músculos } \\
\text { gastrocnêmios e sóleo }\end{array}$ & $\begin{array}{l}\text { Os resultados revelaram } \\
\text { que o a ativação EMG do } \\
\text { sóleo depende mais da } \\
\text { carga da caminhada do } \\
\text { que da velocidade na } \\
\text { água; a ativação do } \\
\text { gastrocnêmio medial } \\
\text { dependente mais da } \\
\text { velocidade. }\end{array}$ \\
\hline $\begin{array}{c}\text { Roesler et al. } \\
\text { MA }\end{array}$ & 2006 & $\begin{array}{l}\text { Analisar o componente } V \text { e AP } \\
\text { da força de reação do solo } \\
\text { (FRS) durante a marcha } \\
\text { aquática e comparar a } \\
\text { influência da velocidade e da } \\
\text { posição dos membros } \\
\text { superiores (MMSS) nos } \\
\text { componentes da FRS. }\end{array}$ & $\begin{array}{c}28 \text { homens e } 32 \\
\text { mulheres, altura } 1,6- \\
1,85 \mathrm{~m} \text {, dividos em } 3 \\
\text { grupos de acordo com o } \\
\text { nível de imersão. Marcha } \\
\text { sobre uma plataforma (a } \\
1,3 \mathrm{~m} \text { de profundidade) } \\
\text { com } 2 \text { células de carga } \\
\text { anexadas, em } 4 \text { diferentes } \\
\text { situações: velocidade } \\
\text { (lenta/rápida) e posição } \\
\text { de MMSS (dentro/fora da } \\
\text { água). Análise do } \\
\text { componente vertical e } \\
\text { antero-posterior da FRS. }\end{array}$ & $\begin{array}{l}\text { Comparando os valores } \\
\text { da marcha com os MMSS } \\
\text { dentro e fora da água, os } \\
\text { resultados foram } \\
\text { significativos para MMSS } \\
\text { fora da água. O } \\
\text { componente vertical a } \\
\text { FRS variou de } 20 \text { a } 40 \% \text {. } \\
\text { O componente AP a FRS } \\
\text { variou de } 8 \text { a } 20 \% \\
\text { considerando os três } \\
\text { níveis de imersão. }\end{array}$ \\
\hline $\begin{array}{c}\text { Chevutschi et al. } \\
\text { MA }\end{array}$ & 2007 & $\begin{array}{c}\text { Definir o grau de ativação } \\
\text { muscular na marcha, a fim de } \\
\text { auxiliar na escolha de exercícios } \\
\text { para a prática clínica de } \\
\text { hidroterapia. }\end{array}$ & $\begin{array}{l}7 \text { mulheres saudáveis; } \\
\text { comparação de EMG do } \\
\text { reto femural, sóleo (perna } \\
\text { direita) e o eretor da } \\
\text { espinha contra lateral } \\
\text { lombar. }\end{array}$ & $\begin{array}{l}\text { Nas duas situações não } \\
\text { houve diferenças tanto } \\
\text { em picos amplitudinais ou } \\
\text { na forma de padrões. A } \\
\text { velocidade do ciclo da } \\
\text { marcha é reduzida em } \\
\text { água, o andar na água } \\
\text { aumenta a atividade dos } \\
\text { eretores da coluna e ativa } \\
\text { o reto femural a níveis } \\
\text { próximos ou superiores } \\
\text { ao caminhar em solo. }\end{array}$ \\
\hline Masumoto; Mercer & 2008 & $\begin{array}{l}\text { Discutir as considerações } \\
\text { metodológicas da mensuração } \\
\text { da atividade muscular da } \\
\text { locomoção na água, resumir os } \\
\text { achados da atividade muscular } \\
\text { na locomoção aquática. }\end{array}$ & $\begin{array}{l}\text { Revisão sistemática - } \\
\text { Atividade EMG na água }\end{array}$ & $\begin{array}{c}\text { Considerações } \\
\text { metodológicas: utilização } \\
\text { de material impermeável } \\
\text { para mensuração na } \\
\text { água. }\end{array}$ \\
\hline $\begin{array}{c}\text { Kotani et al. } \\
\text { MA }\end{array}$ & 2009 & $\begin{array}{l}\text { Medir a ativação muscular na } \\
\text { marcha a fim de estimar a } \\
\text { distância para uma evacuação } \\
\text { segura quando há o efeito do } \\
\text { fluxo e mudanças de } \\
\text { velocidade. }\end{array}$ & $\begin{array}{c}8 \text { home } \\
\text { ns saudáveis; caminhada } \\
\text { contra fluxo de água em } 4 \\
\text { diferentes velocidades }(0, \\
0.47,0.76 \text {, e } 1.12 \mathrm{~m} / \mathrm{s}) ; \\
\text { caminhada em terreno } \\
\text { seco. EMG: reto femural, } \\
\text { vasto lateral, bíceps } \\
\text { femoral, gastrocnêmio, } \\
\text { tibial anterior, glúteos } \\
\text { médio. }\end{array}$ & $\begin{array}{l}\text { A ativação dos glúteos } \\
\text { médio aumentou com a } \\
\text { velocidade do fluxo, } \\
\text { sugerindo que o objetivo } \\
\text { tende a ser para } \\
\text { estabilizar a área pélvica } \\
\text { para evitar a queda; o } \\
\text { tibial anterior exibe maior } \\
\text { ativação muscular com o } \\
\text { aumento da velocidade de } \\
\text { fluxo. }\end{array}$ \\
\hline
\end{tabular}


Figura 4: descrição de objetivos, métodos e desfecho para artigos MV - marcha em terrenos variados e diferenças biomecânicas

\begin{tabular}{|c|c|c|c|c|}
\hline Estudo & Ano & Objetivo & Método & Desfecho \\
\hline $\begin{array}{c}\text { Cham, Redfern } \\
\text { MV }\end{array}$ & 2002 & $\begin{array}{l}\text { Quantificar se os indivíduos } \\
\text { modificam a biomecânica da } \\
\text { marcha em terrenos } \\
\text { escorregadios. }\end{array}$ & $\begin{array}{l}8 \text { homens e } 8 \text { mulheres. } \\
\text { Rampa com plataforma de } \\
\text { força embutida, para } \\
\text { diferentes inclinações ( } 0 \text {, } \\
\left.5,10^{\circ}\right) \text { e extensão }(1,8 \mathrm{~m} \\
\text { de comp., } 1 \mathrm{~m} \text { de larg., } 1,4 \\
\text { de ext), revestida com } \\
\text { compensado fino. LEDs } \\
\text { foram anexados em: } \\
\text { acrômio, trocânter maior, } \\
\text { côndilo femoral, maléolo } \\
\text { lateral e pé. } 3 \\
\text { experimentos: base de } \\
\text { referência (sabiam que o } \\
\text { piso estava seco), } \\
\text { expectativa (não sabiam) } \\
\text { e recuperação (sabiam } \\
\text { porque Ihes era dito). }\end{array}$ & $\begin{array}{l}\text { Na "base de referência" as } \\
\text { variáveis cinéticas foram afetadas } \\
\text { com a inclinação da rampa. } \\
\text { Aumento na angulação aumenta a } \\
\text { FRS. Na avaliação cinemática o } \\
\text { apoio do calcanhar desacelera no } \\
\text { final da fase de balanço. Na } \\
\text { "expectativa": a FRS foi } 16-33 \% \\
\text { menor em comparação com a de } \\
\text { referencia, com maior diminuição } \\
\text { quando aumentava a angulação da } \\
\text { rampa. Adaptações posturais e } \\
\text { temporais da marcha que afetaram } \\
\text { a FRS, foram utilizados para } \\
\text { reduzir o pico de FRS. Adaptações } \\
\text { da marcha incluiu a redução da } \\
\text { duração do apoio. A diminuição do } \\
\text { comprimento do passo diminuiu o } \\
\text { ângulo do pé e a velocidade } \\
\text { angular no contato do calcanhar. } \\
\text { As adaptações realizadas para } \\
\text { andar em piso escorregadio levou a } \\
\text { mudar o momento angular das } \\
\text { articulações. }\end{array}$ \\
\hline $\begin{array}{c}\text { Wade; Redfern } \\
\text { MV }\end{array}$ & 2007 & $\begin{array}{l}\text { Determinar a viabilidade do uso } \\
\text { de plataformas de força para } \\
\text { medir a FRS durante a marcha } \\
\text { em superfícies de cascalho } \\
\text { (especificamente a viabilidade e } \\
\text { precisão de plataformas de } \\
\text { força sob o cascalho, para } \\
\text { medir a FRS da marcha) }\end{array}$ & $\begin{array}{c}5 \text { indivíduos; passarela de } \\
5 \times 8,5 \mathrm{~m} \text {, cobertura de vinil } \\
\text { sobre o chão e } \\
\text { plataformas, cobertura de } \\
\text { cascalho (alturas: } 31,63, \\
101 \mathrm{~mm} \text { ); teste estático } \\
\text { para averiguar FRS } \\
\text { segundo localização e } \\
\text { altura de cobertura; } \\
\text { testes de marcha com } \\
\text { velocidade auto- } \\
\text { selecionada e sem/com } \\
\text { cobertura - apoio no } \\
\text { centro da plataforma }\end{array}$ & $\begin{array}{l}\text { A cobertura de cascalho não afetou } \\
\text { a capacidade da plataforma de } \\
\text { medir com precisão as FRS; na } \\
\text { marcha observou-se que as curvas } \\
\text { de FRS demonstraram as } \\
\text { similaridades entre as condições de } \\
\text { superfície; valores de FRS foram os } \\
\text { mesmos na macha para todas as } \\
\text { superfícies }\end{array}$ \\
\hline $\begin{array}{c}\text { Verhoeff et al. } \\
\text { MV }\end{array}$ & 2009 & $\begin{array}{l}\text { investigar o efeito de um } \\
\text { sistema de biofeedback (BF) na } \\
\text { oscilação do tronco (OT) na } \\
\text { caminhada, com aplicação de } \\
\text { dupla tarefa (DT) }\end{array}$ & $\begin{array}{l}13 \text { idosos e } 16 \text { jovens } \\
\text { saudáveis; realizar } \\
\text { marcha com giroscópios } \\
\text { corpo (L1-3) para medir a } \\
\text { oscilação; as tarefas na } \\
\text { marcha: andar normal, } \\
\text { andar com contagem } \\
\text { decrescente (-7), andar } \\
\text { carregando uma bandeja } \\
\text { com copos de água }\end{array}$ & $\begin{array}{l}\text { Ângulo de oscilação corporal não } \\
\text { se alterou significativamente após } \\
\text { a adição da DT cognitiva; a tarefa } \\
\text { motora envolveu uma redução } \\
\text { significativa na OT; os jovens } \\
\text { reagiram ao BF ao caminhar e } \\
\text { realizaram a DT ao mesmo tempo; } \\
\text { os idosos reduziram ação do tronco } \\
\text { (com BF) na caminhada normal, } \\
\text { menor capacidade de reagir ao BF } \\
\text { e reduzir a OT quando a tarefa } \\
\text { cognitiva ou motora foi adicionada } \\
\text { (o acréscimo pode ter excedido a } \\
\text { capacidade de processamento } \\
\text { disponível); a OT não diminuiu em } \\
\text { idosos, porém o desempenho da } \\
\text { tarefa cognitiva melhorou com BF }\end{array}$ \\
\hline
\end{tabular}


Figura 5: descrição de objetivos, métodos e desfecho para artigos CAT - comparação marcha aquática e terrestre

\begin{tabular}{|c|c|c|c|c|}
\hline Estudo & Ano & Objetivo & Método & Desfecho \\
\hline $\begin{array}{c}\text { Miyoshi et al. } \\
\text { CAT }\end{array}$ & 2004 & $\begin{array}{c}\text { Comparar as FRS, } \\
\text { deslocamentos articulares, } \\
\text { momentos articulares e a } \\
\text { atividade de EMG que ocorre } \\
\text { durante a marcha em diferentes } \\
\text { velocidades no solo e na água. }\end{array}$ & $\begin{array}{c}50 \text { homens saudáveis. Na } \\
\text { água, a profundidade era } \\
\text { ajustada até que o peso } \\
\text { corporal reduzisse a } 80 \% \text {. } \\
\text { Realizada análise por } \\
\text { video, com auxílio de } \\
\text { plataforma de força para } \\
\text { as variáveis cinéticas e } \\
\text { cinemáticas de quadril, } \\
\text { joelho e tornozelo. EMG }\end{array}$ & $\begin{array}{l}\text { O componente AP difere entre a } \\
\text { água e solo; o médio-lateral é } \\
\text { similar. O deslocamento angular da } \\
\text { articulação do quadril e tornozelo } \\
\text { são similares na água e solo. A } \\
\text { amplitude de movimento (ADM) de } \\
\text { joelho é menor na água que no } \\
\text { solo. O momento articular das três } \\
\text { articulações foi menor na água que } \\
\text { em solo no apoio, o momento de } \\
\text { extensão do quadril e a atividade } \\
\text { EMG dos extensores de quadril } \\
\text { estavam aumentadas, como a } \\
\text { velocidade da marcha na água. }\end{array}$ \\
\hline $\begin{array}{c}\text { Miyoshi et al. } \\
\text { CAT }\end{array}$ & 2005 & $\begin{array}{l}\text { Explicar o papel do momento } \\
\text { articular de membro inferior e } \\
\text { sua contribuição nas tarefas de } \\
\text { sustentação e propulsão da } \\
\text { marcha, em ambiente aquático } \\
\text { e terrestre }\end{array}$ & $\begin{array}{c}\text { Cinemática, EMG de } \\
\text { bíceps femoral e glúteo } \\
\text { máximos e FRS foram } \\
\text { medidos nas condições: } \\
\text { andar em terra e água em } \\
\text { ritmo auto-determinado, } \\
\text { andar devagar na terra, } \\
\text { caminhar rapido na água } \\
\text { com/sem carga adicional } \\
\text { ( } 8 \mathrm{~kg})\end{array}$ & $\begin{array}{l}\text { O momento de flexão plantar do } \\
\text { tornozelo teve alta sensibilidade ao } \\
\text { peso e menor à velocidade da } \\
\text { marcha; a principal função deste } \\
\text { momento é manter a estabilidade } \\
\text { contra a gravidade. A força do } \\
\text { impacto em ambas as condições } \\
\text { aumentaram com o peso das } \\
\text { cargas e/ou da velocidade da } \\
\text { marcha; a principal função do } \\
\text { momento articular do joelho é } \\
\text { absorver a força de impacto na } \\
\text { marcha. Andar na água reduziu a } \\
\text { carga e aumentou a força para } \\
\text { mover o corpo à frente (empuxo e } \\
\text { resistência) - uma forte propulsão } \\
\text { é necessária para o deslocamento; } \\
\text { o momento da articulação do } \\
\text { quadril é de extensão (fase de } \\
\text { apoio) e aumenta à medida que a } \\
\text { velocidade aumenta (água); a } \\
\text { principal função deste momento é } \\
\text { impulsionar o corpo à frente contra } \\
\text { a resistência da água }\end{array}$ \\
\hline $\begin{array}{c}\text { Barela et al. } \\
\text { CAT }\end{array}$ & 2006 & $\begin{array}{c}\text { Caracterizar qualitativamente e } \\
\text { quantitativamente um ciclo } \\
\text { completo da marcha de adultos } \\
\text { em água rasa e comparar com } \\
\text { a marcha terrestre. }\end{array}$ & $\begin{array}{l}10 \text { adultos ( } 6 \text { homens e } 4 \\
\text { mulheres). Análise da } \\
\text { marcha bidimensional, } \\
\text { água no processo xifóide } \\
\text { de cada indivíduo. Uso de } \\
\text { marcadores reflexivos: } \\
\text { cabeça do } 5^{\circ} \text { metatarso, } \\
\text { maléolo lateral, epicôdilo } \\
\text { lateral do fêmur, trocanter } \\
\text { e } 5 \mathrm{~cm} \text { abaixo e lateral do } \\
\text { processo xifóide. EMG: } \\
\text { TA, VL, BF, tensor da } \\
\text { fáscia lata (TFL), glúteos } \\
\text { (G) e eretor da espinha } \\
\text { (ES). Plataforma de força } \\
\text { para componentes V e AP } \\
\text { de FRS. }\end{array}$ & $\begin{array}{c}\text { Qualitativamente todas as } \\
\text { articulações obtiveram padrões } \\
\text { semelhantes no ciclo em ambos os } \\
\text { ambientes. O padrão do tornozelo } \\
\text { na água foi de flexão plantar para } \\
\text { as fases de apoio e balanço. O } \\
\text { joelho apresentou redução da } \\
\text { flexão durante os primeiros } 15 \% \text { o } \\
\text { ciclo (água) e esteve mais } \\
\text { estendido na fase de apoio na água } \\
\text { do que em solo. O padrão do } \\
\text { quadril foi similar em ambos. } \\
\text { Qualitativamente, na água, os } \\
\text { segmentos apresentaram postura } \\
\text { neutra no início e no final das } \\
\text { fases. A amplitude de movimento } \\
\text { de tornozelo, joelho e tronco foi a } \\
\text { mesma para água e solo; nos } \\
\text { segmentos pé, perna e tronco } \\
\text { houve diferença entre os } \\
\text { ambientes. O componente } V \text { e AP } \\
\text { da FRS foi diferente nas duas } \\
\text { condições. EMG: G apresentou } \\
\text { padrão similar em ambos os } \\
\text { ambientes. TA e TFL foram } \\
\text { ativados na fase de balanço, BF e } \\
\text { VL na de apoio e ES no final desta } \\
\text { e em toda a de balanço. RA na fase } \\
\text { de contato. }\end{array}$ \\
\hline
\end{tabular}


Figura 6: descrição de objetivos, métodos e desfecho para artigos CAT - comparação marcha aquática e terrestre; AAM - análise antropológica da marcha; OU - outros

\begin{tabular}{|c|c|c|c|c|}
\hline Estudo & Ano & Objetivo & Método & Desfecho \\
\hline $\begin{array}{c}\text { Barela; Duarte } \\
\text { AAM }\end{array}$ & 2008 & $\begin{array}{l}\text { Comparar qualitativamente e } \\
\text { quantitativamente a marcha de } \\
\text { idosos saudáveis na água e no } \\
\text { solo. Comparar a marcha na } \\
\text { água e em solo de idosos com o } \\
\text { estudo prévio (Barela; Stolf; } \\
\text { Duarte, 2005) realizado com } \\
\text { adultos jovens. }\end{array}$ & $\begin{array}{c}10 \text { idosos ( } 6 \text { homens e } 4 \\
\text { mulheres). Análise da } \\
\text { marcha bidimensional, } \\
\text { água no processo xifóide } \\
\text { de cada indivíduo. Braços } \\
\text { na superfície da água.Uso } \\
\text { de marcadores reflexivos: } \\
\text { cabeça do } 5^{\circ} \text { metatarso, } \\
\text { maléolo lateral, epicôdilo } \\
\text { lateral do fêmur, trocanter } \\
\text { e } 5 \mathrm{~cm} \text { abaixo e lateral do } \\
\text { processo xifóide. EMG: } \\
\text { TA, VL, BF, TFL, G e ES. } \\
\text { Plataforma de força para } \\
\text { as componentes V e AP de } \\
\text { FRS. }\end{array}$ & $\begin{array}{l}\text { Não houve diferença na duração do } \\
\text { passo (solo) entre grupos, idosos } \\
\text { apresentaram menor duração na } \\
\text { água. Em solo, a velocidade da } \\
\text { marcha de idosos é menor que a } \\
\text { de adultos jovens, mas é igual na } \\
\text { água. Qualitativamente todas as } \\
\text { articulações obtiveram padrões } \\
\text { semelhantes na marcha (dois } \\
\text { ambientes). Padrão do tornozelo: } \\
\text { na água foi de flexão plantar para } \\
\text { o apoio e final do balanço; toque } \\
\text { no solo realizado com o pé } \\
\text { aplanado, não com o calcanhar.O } \\
\text { joelho apresentou maior flexão no } \\
\text { início e final do ciclo (água e solo). } \\
\text { Padrão do quadril: flexão em todo } \\
\text { o ciclo no solo e água. A ADM de } \\
\text { tornozelo (idosos) foi menor que } \\
\text { dos adultos jovens. ADM de joelho } \\
\text { foi menor na água que no solo } \\
\text { (dois grupos). Idosos tem maior } \\
\text { flexão de joelho na fase de apoio } \\
\text { na água e comparado a adultos } \\
\text { jovens. No balanço, idosos tiveram } \\
\text { menor dorsiflexão na água que } \\
\text { adultos jovens. Adultos jovens } \\
\text { realizaram maior flexão de joelho } \\
\text { (solo) e idosos maior flexão de } \\
\text { quadril (água). FRS: o primeiro } \\
\text { pico do componente V foi menor } \\
\text { em idosos e na água; o segundo foi } \\
\text { menor na água para os dois } \\
\text { grupos. O impacto é menor em } \\
\text { idosos e na água, para os dois } \\
\text { grupos. O impulso horizontal é } \\
\text { menor no solo e na água para } \\
\text { idosos.EMG: G atividade de pico na } \\
\text { água menor que em solo. TFL } \\
\text { foram ativados na fase de balanço } \\
\text { na água, BF e VL no apoio na } \\
\text { água, TA em ambas as fases, ES } \\
\text { no final do apoio e durante todo o } \\
\text { balanço. RA em pontos na fase de } \\
\text { contato. }\end{array}$ \\
\hline $\begin{array}{l}\text { Preuschoft } \\
\text { AAM }\end{array}$ & 2004 & $\begin{array}{l}\text { Discutir as características } \\
\text { morfológicas gerais da maioria } \\
\text { das espécies (mecânica teórica } \\
\text { e descritiva do esqueleto e } \\
\text { proporções - chimpanzés, } \\
\text { orangotangos, gorilas, gibões, } \\
\text { siamangs, humanos modernos) }\end{array}$ & não descrita & $\begin{array}{c}\text { A bipedalidade do homem moderno } \\
\text { tem diversas fontes de explicação, } \\
\text { por referências aos membros } \\
\text { superiores ou simplesmente em } \\
\text { termos de melhorias que reduzam } \\
\text { o custo do andar abaixo, de modo } \\
\text { que grandes distâncias fossem } \\
\text { cobertas em velocidade } \\
\text { considerável para um consumo de } \\
\text { energia mínimo }\end{array}$ \\
\hline $\begin{array}{c}\text { Kuliukas et al. } \\
\text { AAM }\end{array}$ & 2009 & $\begin{array}{c}\text { Analisar as duas possíveis } \\
\text { formas de locomoção de } \\
\text { australopitecos, qual tem } \\
\text { padrão de maior desgaste } \\
\text { energético }\end{array}$ & $\begin{array}{c}30 \text { voluntários; os } \\
\text { indivíduos foram } \\
\text { submetidos à testes } \\
\text { dentro da água com } \\
\text { diferentes graus de flexão } \\
\text { de joelho, na posição } \\
\text { vertical. }\end{array}$ & $\begin{array}{l}\text { Em águas profundas percebe-se } \\
\text { que o gasto enérgético da } \\
\text { locomoção com os joelhos } \\
\text { flexionados não é tão grande } \\
\text { quanto percebido na locomoção no } \\
\text { ambiente terrestre. }\end{array}$ \\
\hline $\begin{array}{l}\text { House et al. } \\
\text { OU }\end{array}$ & 2004 & $\begin{array}{l}\text { Testar a eficiência de palmilhas } \\
\text { para treinamento de militares, } \\
\text { verificando a dimunição da } \\
\text { retenção de líquidos. }\end{array}$ & $\begin{array}{c}\text { Militares utilizaram as } \\
\text { palmilhas nas semanas } 12 \\
\text { e } 30 \text { de treinamento, } \\
\text { análise de aspectos } \\
\text { biomecânicos da pressão } \\
\text { sobre o bico do pé e o } \\
\text { calcanhar. }\end{array}$ & $\begin{array}{l}\text { As palmilhas são suficientemente } \\
\text { duráveis para militares; a retenção } \\
\text { de água foi reduzida, diminuindo os } \\
\text { ferimentos decorrentes do não } \\
\text { congelamento dos pés. }\end{array}$ \\
\hline $\begin{array}{l}\text { Prendergast; Lee } \\
\text { OU }\end{array}$ & 2006 & $\begin{array}{c}\text { Analisar contribuições do autor } \\
\text { para a biomecânica: ênfase a } \\
\text { teoria da hidrodinâmica da } \\
\text { lubrificação das articulações }\end{array}$ & $\begin{array}{c}\text { Análise de livros e } \\
\text { publicações de MacConaill }\end{array}$ & $\begin{array}{l}\text { O autor tem um grande papel } \\
\text { científico na área de estudos sobre } \\
\text { as articulações do joelho. Após o } \\
\text { ano de } 1930, \text { MacConaill aplicou } \\
\text { uma abordagem matemática para } \\
\text { combater cada problema. }\end{array}$ \\
\hline
\end{tabular}




\section{DISCUSSÃO}

Para o encadeamento, discorre-se sobre os artigos segundo o agrupamento por objetivos de pesquisa, tal qual a organização dos resultados.

Os primeiros estudos descritos abordam as características e comportamentos da marcha aquática (MA). Miyoshi et al. ${ }^{5}$ aponta que na marcha há variações na ativação muscular, podendo ser influenciada pelo peso do corpo imerso e pela velocidade com a qual este se desloca. A primeira influência é descrita como uma redução no input somatosensorial relacionado pela ação do empuxo; já a segunda, como o aumento dos comandos descendentes dos centros superiores, para possibilitar o transporte do corpo para a frente, contra a resistência da água.

O autor ainda explora mais a questão, dizendo que o comando descendente dos centros superiores, relacionados à maior força propulsiva, aparecem seletivamente para ativar o neurônio motor do músculo responsável pela ação; ou seja, a solicitação é direta e seletiva, sendo concebível relacioná-la ao esforço direto ou papel deste motoneurônio em superar a resistência do movimento dentro da água. Para Kotani et al. ${ }^{14}$ esta ativação depende da associação entre o tipo do músculo solicitado (monoarticular/biarticular) e sua função. Os autores também estabelecem que variação no tempo desta ativação está relacionado à existência de um fluxo de água ao encontro do corpo em deslocamento: ela aumentará segundo o aumento deste fluxo.

Quanto à influência do peso do corpo imerso, determinado pelas suas características e pela ação do empuxo, Roesler et al. ${ }^{11}$ confirmam que o nível de imersão e a posição dos membros superiores (variação de peso) determinam maiores respostas de força de reação do solo (FRS) na marcha. Esta idéia é corroborada por Masumoto e Mercer $^{2}$, pois afirmam que a ativação muscular se dá pelo input somatosensorial de peso - uma relação características corporais e sua consequente ação do empuxo. Os autores explicam que o empuxo modifica a ação gravitacional no meio aquático diminuindo as reações de solo e, por sua vez, o input somatosensorial relacionado. Esta redução determina uma menor ativação muscular, além de modificar a influênia da pressão hidrostática, alterando a ação muscular mediada por receptores corporais de pressão.

A velocidade de deslocamento de um corpo na água se comporta segundo a interação de alguns fatores: a influência da área do corpo submerso e a resistência aquática imposta, pois a relação dessa resistência com a velocidade se dá em uma proporção quadrada5; a viscosidade do meio ${ }^{2}$. Esta interação se efetiva pela posição vertical do corpo durante a execução da marcha, pois com o aumento da área frontal, da resistência e da interação entre o corpo e o meio (viscosidade), há uma redução na velocidade em relação ao meio terrestre ${ }^{2}$. Se a velocidade é resultante da ativação de motoneurônios para um movimento ${ }^{1}$, seja este angular ou linear, então há grande ativação para vencer a resistência da água, pois é muito maior que a do $a r^{2}$. Alguns ajustes motores e funcionais são realizados para o aumento da velocidade, como: a alteração da manutenção da postura pelos músculos eretores, que estabilizam em plano frontal para baixas velocidades e alternam para plano sagital em velocidades maiores; e a redução na frequência no passo em relação ao movimento na terra, em consequência do empuxo e do arrasto hidrodinâmico ${ }^{13}$.

Quanto às variações das superfícies (MV), os estudos encontrados relatam que, quando o corpo encontra ambiente diferente daquele no qual desenvolve a rotina para a marcha, este necessita realizar adaptações potenciais, resultando em diferenças significativas na biomecânica da marcha ${ }^{15,16}$. Cham e Redfern ${ }^{15}$ comentam em sua pesquisa que as adaptações realizadas para andar em piso escorregadio alteram o momento angular das articulações, isto está associado ao conceito de equilíbrio na biomecânica. Este equilíbrio é onde as articulações assumem uma postura estável, a qual Caromano ${ }^{2}$ menciona, afirmando que este ocorre quando diversas forças agem sobre o corpo, atuando em direções opostas e se anulam. Este equilíbrio também é observado em estudos que pessoas deviam realizar duas tarefas simultaneamente ${ }^{16}$ : nos testes aplicados os participantes tiveram que realizar uma tarefa de raciocínio e realizar uma ação motora, fazendo adaptações da postura em busca do equilíbrio para atingir um determinado objetivo.

A comparação da marcha em diferentes meios e pessoas é foco de pesquisa em seres humanos, considerando as diversas fases de evolução: Preuschoft ${ }^{21}$ demostra o interesse em estudar as diferenças da marcha nos australopitecos e como esta forma influenciou a locomoção na atualidade. Verificou que em águas profundas o gasto energético da locomoção com os joelhos flexionados, forma da locomoção dos australopitecos, não é tão grande quanto percebido na locomoção no ambiente terrestre. O autor atribuiu tal diferença a menor atividade encontrada nos músculos gastrocnêmio e sóleo no exercício aquático, justificada pela ausência de contato e consequentes forças verticais com o fundo da piscina, durante a caminhada neste meio ${ }^{3}$.

Os estudos relacionados com a comparação da marcha aquática e terrestre (CAT) justificam seus resultados relacionando com as propriedades de empuxo, arrasto hidrodinâmico e viscosidade da água.

Miyoshi et al. ${ }^{19}$ e Barela et al. ${ }^{20}$ relatam que a diminuição do componente vertical da FRS está relacionada com o empuxo, que influencia na redução da força de impacto na fase inicial do apoio na água. O que vai ao encontro do estudo de Masumoto e Mercer $^{2}$, que relatam a redução em $71 \%$ do peso corporal quando a água está na altura do processo xifóide, o que pode estar relacionado com a diminuição do componente vertical da FRS. 
Barela et al. ${ }^{20}$ acrescenta que a diminuição da força vertical está relacionada com a diminuição da velocidade da marcha realizada na água comparado com o solo. Considerando que as características de área e viscosidade contribuem para as alterações ${ }^{2}$, corrobora-se que a velocidade da marcha aquática é metade da velocidade em solo ${ }^{4}$.

No entanto, Barela et al. ${ }^{18}$ e Barela et al. ${ }^{20}$ explicam que a diferença encontrada na marcha aquática e terrestre não se deve somente à influência do meio, mas a também às diferentes velocidades utilizadas durante o deslocamento, à diminuição do peso corporal na água devido ao empuxo e às alterações necessárias para vencer o arrasto hidrodinâmico. De acordo com os princípios da hidrodinâmica, os movimentos de segmentos dentro da água são influenciados pela força de arrasto e pelo empuxo ${ }^{28}$, o que diferencia do ambiente terrestre.

Achados eletromiográficos definem a baixa velocidade, desenvolvida durante a marcha na água, como elemento fundamental para vencer o arrasto hidrodinâmico e, além disso, consideram que é a diminuição de peso que gera menor impulso propulsor para o deslocamento na água ${ }^{18,20}$.

Neste raciocínio, a diminuição da atividade muscular durante a marcha aquática comparada com a terretre está relacionada com alterações da marcha: Masumoto et al.5, em seu estudo, verificaram diminuição da freqüência do passo (aproximadamente $57 \%$ em relação ao solo) e diminuição do comprimento do passo na água em relação ao solo. A diminuição da atividade muscular na água pode estar relacionada com o empuxo e a diminuição da força da gravidade e da pressão hidrostática que atuam no sistema neuromuscular².

Barela et al. ${ }^{18}$ e Barela et al. ${ }^{20}$ não encontraram diferenças na amplitude de movimento (ADM) das articulações tanto no solo quanto na água, porém com relação aos segmentos, pés, pernas e tronco, houve diferença considerando os dois ambientes, devido à manutenção do membro em posição neutra durante o deslocamento na água para vencer a força de arrasto, o que vai ao encontro do estudo de Ribas et al. ${ }^{1}$.

Miyoshi et al. ${ }^{19}$, sugerem que a diminuição da plantiflexão de tornozelo e da extensão de joelho é devido ao empuxo e que, em seu estudo, a articulação de joelho não possui papel absorção de impacto na água. No estudo de Ribas et al. ${ }^{1}$, na fase de apoio inicial e oscilação final, a extensão articular do joelho no ambiente terrestre é maior quando comparada em ambiente aquático e a flexão do joelho, na fase de balanço, é maior no ambiente aquático em virtude da tentativa de diminuir a resistência frontal da água.

Miyoshi et al. ${ }^{19}$ e Miyoshi et al. ${ }^{6}$ justificam que a redução do peso corporal do indivíduo ao andar dentro da água e o aumento da força necessária para mover o corpo nesse ambiente é decorrente, respectivamente, do empuxo e da resistência aquática, especificamente a viscosidade.
Argumentam também que o aumento do momento angular no quadril na extensão, durante a fase de apoio, é decorrente da força de impulsão necessária para deslocar o corpo na água. Respostas similares para a ativação dos músculos propulsores da caminhada são encontradas em investigações com velocidade fixa (mesma intensidade fisiológica de exercício) 26, 23 em músculos responsáveis pela propulsão do movimento.

Na realização de uma mesma intensidade de esforço fisiológico nos dois meios, a velocidade da marcha terrestre precisa ser o dobro da velocidade aquática ${ }^{23}$. Da mesma forma a atividade aumentada de músculos como o gastrocnêmio, o tibial anterior, vasto medial, o reto femoral e o bíceps femoral no meio aquático ocorre devido ao aumento da resistência imposta ao movimento pela necessidade de vencer a maior densidade do fluído líquido comparado com a do ar em uma mesma velocidade de exercício terrestre ${ }^{23,28}$.

Miyoshi et al. ${ }^{6}$ enfocam que aumento na flexão plantar do tornozelo ocorre se a instabilidade corporal, o peso corporal e a velocidade aumentarem, o que indica que maior alteração do momento articular é necessário para manter a estabilidade contra a gravidade. Miyoshi et al. ${ }^{19}$, relata o aumento dos momentos articulares e das ativações musculares em função do aumento da velocidade de deslocamento na água. Estas observações sugerem que atividades musculares podem ser ativadas com pequenas mudanças na velocidade de deslocamento na água em relação ao solo, o que pode ser decorrente do aumento exponencial do arrasto hidrodinâmico que influencia a velocidade de movimento durante a locomoção na água, uma vez que, a relação entre a força de arrasto e a velocidade de movimento é não linear, de modo que, o arrasto aumenta em função da velocidade ao quadrado ${ }^{6}$.

As alterações que o corpo sofre começam ao primeiro contato com o meio, mas é por meio do deslocamento que os efeitos da resistência são experimentados. Os artigos descritos neste estudo estabelecem que as alterações do comportamento motor têm por base os reflexos sinestésicos (receptores de visão, tato, etc), os reflexos de movimento e de carga nas ativações sensóriomotoras correspondentes, nas consequentes ações musculares e, por fim, nas mudanças passíveis de observação: cinemáticas (linear, angular), etc. Algumas limitações foram identificadas com este estudo: as palavras-chave escolhidas e utilizadas estão longe de abranger os estudos correspondentes às áreas responsáveis pela produção deste conhecimento; apenas uma base de dados foi utilizada para a pesquisa dos artigos, o que reduziu os estudos passíveis de análise nas condições aqui especificadas. Indica-se o aprofundamento desta pesquisa com um maior número de palavras e de bases de dados, para que o tema aqui analisado possa ser discutido com mais profundidade. 


\section{REFERÊNCIAS}

1. Ribas DIR, Israel VL, Manfra EF, Araújo CC. Estudo comparativo dos parâmetros angulares da marcha humana em ambiente aquático e terrestre em indivíduos hígidos adultos jovens. Rev Bras Med Esporte. 2007; 13(6). DOI 10.1590/S1517-86922007000600003.

2. Masumoto K; Mercer JA. Biomechanics of human locomotion in water: an electomyographic analysis. Exerc Sport Sci Rev. 2008; 36(3): 160-9.

3. Maglischo E. Swimming Fastest. Human Kinetics. 2003. USA.

4. Tucher G, Gomes ALM, Dantas EHM. Relação entre a potência mecânica de nado e o rendimento na natação. Rev. Bras. Cienc. Esporte. 2009; 30 (2): 169-180.

5. Miyoshi T, Nakazawa K, Tanizaki M, Sato T, Akai, M. Altered activation pattern in synergistic ankle plantarflex or muscles in a reduced-gravity environment. Gait Posture. 2006; 24(1): 94-9.

6. Miyoshi T, Shirota T, Yamamoto SI., Nakazawa $\mathrm{K}$, Akai M. Functional roles of lower-limb joint moments while walking in water. Clinical Biomechanics. 2005; 20: 194-201.

7. Canderolo JM, Caromano FA. Revisão e atualização sobre a graduação da resistência ao movimento durante a imersão na água. Revista Fisioterapia Brasil. 2004; 5(1).

8. Alonso VK, Okaji SS, Pinheiro MT, Ribeiro CM, Souza HP, Santos SS. Análise cinemática da marcha em pacientes hemiparéticos. Revista Fisio Brasil. 2002;

9. Mann L, Teixeira CS, Mota CB. A marcha humana: interferências de cargas e de diferentes situações. Arq. Ciênc. Saúde Unipar. 2008; 12 (3): 257-264.

10. Kirkwood RN, Gomes HA, Sampaio RF, Culham E, Costigan P. Análise Biomecânica das Articulações do Quadril e Joelho Durante a Marcha em Participantes Idosos. Acta Ortop Bras. 2007; 15(5): 267-271.

11. Roesler H, Brito RN, Haupenthal A, Souza PV. Análise comparativa da marcha humana em solo à subaquática em dois níveis de imersão: joelho e quadril. Revista Brasileira de Fisioterapia. 2004; 8:1-6.

12. McGibbon CA, Krebs DE. Age-Related Changes in Lower Trunk Coordination and Energy Transfer During Gait. J Neurophysiol. 2001; 85: 1923-1931.

13. Chevutschi A, Lensel G, Vaast D, Thevenon A. An electromyographic study of human gait both in water and on dry ground. J Physiol Anthropol. 2007; 26(4): 467-7. DOI 10.2114/jpa2.26.467

14. Kotani $K$, Hirato $Y$, Ishigaki $T$, Shimada $H$, Toda $\mathrm{K}$, Horii K. Biomechanical analysis of walking through a hallway under flooded conditions. J Physiol Anthropol. 2009; 28(1): 23-28.

15. Cham R, Redfern MS. Changes in gait when anticipating slippery floors. Gait Posture. 2002; 15(2): 159-71.
16. Verhoeff LL, Horlings CG, Janssen LJ, Bridenbaugh SA, Allum JH. Effects of biofeedback on trunk sway during dual tasking in the healthy young and elderly. Gait Posture. 2009; 30(1): 76-81.

17. Wade C, Redfern MS. Ground reaction forces during human locomotion on railroad ballast. J Appl Biomech. 2007; 23(4): 322-9.

18. Barela AM, Stolf SF, Duarte M. Biomechanical characteristics of adults walking in shallow water and on land. Journal of Electromyography and Kinesiology. 2006; 16: 250-256. DOI 10.1016/j.jelekin.2005.06.013

19. Miyoshi T, Shirota T, Yamamoto S, Nakazawa $\mathrm{K}$, Akai M. Effect of the walking speed to the lower limb joint angular displacements, joint moments and ground reaction forces during walking in water. Disabil Rehabil. 2004; 26(12): 724-32.

20. Barela AMF, Duarte M. Biomechanical characteristics of elderly individuals walking on land and in water. Journal of Electromyography and Kinesiology. 2008; 18: 446-454. DOI 10.1016/j.jelekin.2006.10.008

21. Preuschoft H. Mechanisms for the acquisition of habitual bipedality: are there biomechanical reasons for the acquisition of upright bipedal posture? J Anat. 2004; 204(5): 363-84.

22. Kuliukas AV, Milne N, Fournier P. The relative cost of bent-hip bent-knee walking is reduced in water. Homo. 2009; 60(6): 479-88.

23. Masumoto K, Shono T, Hotta N, Fujishima K. Muscle activation, cardiorespiratory response, and rating of perceived exertion in older subjects while walking in water and on dry land. J. Electromyogr. Kinesiol. 2008;18(4):581-90.

24. Caromano, FA. Movimentos na água. Revista Fisioterapia Brasil. 2003; 4(2).

25. Silva, EM; Kruel, LFM. Caminhada em Ambiente Aquático e Terrestre: Revisão de Literatura Sobre a Comparação das Respostas Neuromusculares e Cardiorrespiratórias. Rev Bras Med Esporte. 2008; 14(6). DOI 10.1590/ S1517-86922008000600016

26. Masumoto KS, Takasugi N, Hotta K, Fujishima, Iwamoto $Y$. Electromyographic analysis of walking in water in healthy humans. J. Physiol. Anthropol. Appl. Human Sci. 2004; 23: 119127.

27. Masumoto K, Shono T, Takasugi S, Hotta N, Fujishima K, Iwamoto, Y Age-related differences in muscle activity, stride frequency and heart rate response during walking in water. Journal of Electromyography and Kinesiology. 2007; 17: 596-604.

28. Pöyhönen $T$, Kyröläinen $H$, Keskinen $K L$, Hautala A, Savolainen J, Mälkiä E. Electromyographic and kinematic analysis of therapeutic knee exercises under water. Clin.Biomech. 2001; 16: 496-504. DOI: 10. 